\title{
Accuracy of Peak Systolic Velocity of Radial Artery as Predictor of Maturation of Radiocephalic Arteriovenous Fistula in Cipto Mangunkusumo Hospital \\ Dedy Pratamaa*, Richard Yehuda Limen ${ }^{b}$, Akhmadu Muradic
}

Introduction: Hemodialysis is an essential treatment in patients with stage 5 chronic kidney disease (CKD) or End-Stage Renal Disease (ESRD). The maturity of arteriovenous fistulas determines the success of hemodialysis. FAV maturity depends on preoperative preparation. The study aims to examine the preoperative and intraoperative peak systolic velocity (PSV) of the radial artery as a predictor of the successful maturation of the radiocephalic FAV.

Method: This study used an analytic cross-sectional design to obtain the relationship of FAV maturation with preoperative and intraoperative PSV. Subjects were those who will undergo radiocephalic FAV surgery with preoperative ultrasound mapping. Shortly after anastomosis, PSV was measured. After 6 weeks, FAV was assessed for its maturity.

Results: As many as 71 patients were undergone radiocephalic FAV surgery and followed for six weeks. The mean preoperative PSV of mature fistula was significantly higher than immature $(54.6 \pm 11.7 \mathrm{~cm} / \mathrm{s}$ and $26.7 \pm 7.7 \mathrm{~cm} / \mathrm{s} ; \mathrm{p}<0.001)$. The mean intraoperative PSV of mature fistula was significantly higher than immature $(57.9+12.6 \mathrm{~cm} / \mathrm{s}$ and $27.1+8.1 \mathrm{~cm} / \mathrm{s}$; $\mathrm{p}<0.001)$. The mean PSV difference in mature fistulas was significantly higher than immature $(3 \mathrm{~cm} / \mathrm{s}$ and $0 \mathrm{~cm} / \mathrm{s} ; \mathrm{p}<0.001)$. Preoperative PSV with a cut-off of $40 \mathrm{~cm} / \mathrm{s}$, intraoperative with a cut-off of $42 \mathrm{~cm} / \mathrm{s}$, and a difference of PSV with a cut-off of $2 \mathrm{~cm} / \mathrm{s}$ all had $92.9 \%$ accuracy as a predictor of FAV maturation compared to "rule of 6" as a reference standard.

Conclusion: Preoperative PSV $>40 \mathrm{~cm} / \mathrm{s}$ and intraoperative PSV $>42 \mathrm{~cm} / \mathrm{s}$ had a good predictor value for radiocephalic FAV maturation.

Keywords: peak systolic velocity, maturation, arteriovenous fistula, radial artery https://doi.org/10.36864/jinasvs.2020.1.008
Copyright (C) 2020, The Indonesian Society for Vascular and Endovascular Surgery

JINASVS 2020;1(1):30-33

*Correspondence: dedygpratama@yahoo.com

aM.D., Vascular and Endovascular Division, Department of Surgery, Cipto Mangunkusumo Hospital - Faculty of Medicine, Universitas Indonesia, Jakarta, Indonesia

${ }^{b}$ M.D., Department of Surgery, Siloam Hospital Balikpapan, East Kalimantan, Indonesia

cM.D., Ph.D., Vascular and Endovascular Division, Department of Surgery, Cipto Mangunkusumo Hospital - Faculty of Medicine, Universitas Indonesia, Jakarta, Indonesia

\section{INTRODUCTION}

Hemodialysis is an essential treatment in patients with stage 5 chronic kidney disease (CKD) or End-Stage Renal Disease (ESRD). On the other hand, hemodialysis can also cause complications, one of which is cardiovascular events and infections. Before undergoing hemodialysis, vascular access is needed, such as arteriovenous fistula (FAV) or dialysis catheter. The main goal of using hemodialysis access in patients with stage 4 or 5 CKD is to maintain long-term functional access with minimal complications. The choice of access depends on age, sex, life expectancy, anatomy, comorbidity, the likelihood of success (maturity rate of arteriovenous fistula, long-term patency of access with prosthetic graft), the importance of dialysis, and the patient's desire. One of the first and best choices for hemodialysis access is arteriovenous fistula. ${ }^{1,2}$

The data shows the failure rate of native FAV ranges between $20-60 \%$. The maturity of arteriovenous fistulas determines the success of vascular access to hemodialysis. Usually, an arteriovenous fistula is ready for use within 6-8 weeks after the procedure. Based on KDOQI guidelines, the criteria for the maturity of arteriovenous fistula access suitable for cannulation are defined as the "rule of $6 \mathrm{~s}$ ", which are minimum of $6 \mathrm{~mm}$ venous diameter, a minimum venous flow rate of $600 \mathrm{~mL} / \mathrm{min}$, and a maximum venous depth from the skin of $6 \mathrm{~mm} .^{1,3-8}$

Preoperative peak systolic velocity (PSV) radial artery measurements can be performed to predict the maturation of the radiocephalic 
Table 1. Characteristics of patients included in the study $(n=71)$

\begin{tabular}{lcc}
\hline \multicolumn{1}{c}{ Variable } & $\mathrm{n}(\%)$ & Mean $\pm \mathrm{SD}$ \\
\hline Age (years) & & $53,59 \pm 7,75$ \\
Gender & $40(56,3)$ & \\
Men & $31(43,7)$ & \\
Women & & \\
Intraoperative data & $182,45 \pm 37,45$ \\
Bloodflow (ml/minute) & $2,68 \pm 0,34$ \\
Diameter of artery (mm) & $2,55 \pm 0,33$ \\
Diameter of vein (mm) & $132,73 \pm 9,67$ \\
SBP (mmHg) & $45,36 \pm 1,99$ \\
Preoperative PSV (cm/s) & $47,74 \pm 2,17$ \\
Intraoperative PSV (cm/s) & $2,38 \pm 0,22$ \\
Difference of PSV (cm/s) &
\end{tabular}

arteriovenous fistula. According to Sedlacek et al., ${ }^{9}$ who showed that the preoperative PSV in the radiocephalic AV fistula of $\geq 50 \mathrm{~cm} / \mathrm{s}$ as a predictor of maturity success. However, the results of a study by Lockhart et al., ${ }^{10}$ reported that there was no difference in the success of arteriovenous fistulas in PSV $<50 \mathrm{~cm} / \mathrm{s}$ with PSV $\geq 50 \mathrm{~cm} / \mathrm{s}$.

The high failure rate of arteriovenous fistulas maturation and the high morbidity due to these failures makes it necessary to find the right measurements for the success of FAV maturation. This study aims to determine the use of preoperative peak systolic velocity (PSV) and shortly after making arteriovenous fistulas as a method that can be used in assessing the success of a FAV.

\section{METHOD}

This study was conducted using a retrospective cohort design study to obtain an association between peak systolic velocity of the preoperative radial artery and shortly after intraoperative using Doppler ultrasonography for maturation of the radiosephalic arteriovenous fistula in patients undergoing hemodialysis.

The study was conducted in the Division of Vascular and Endovascular Surgery Department of Surgery, Cipto Mangunkusumo Hospital, Jakarta, Indonesia. This research was performed from August to December 2018. The population was patients with CKD stage 4-5 who got hemodialysis access therapy by undergone a radiocephalic arteriovenous fistula procedure. This study used total sampling method. Inclusion criteria were patients with stage 4-5 CKD who will undergo a radiocephalic arteriovenous fistula procedure at Cipto Mangunkusumo Hospital from January to May 2018 and systolic blood pressure $>100 \mathrm{mmHg}$ measured intraoperatively during fistula procedure. The exclusion criteria were a history of cannulation before six weeks, patients with hemodialysis catheter attached to the same side as the location of the fistula making, and patients with central venous stenosis.

The data taken was the result of a Doppler ultrasound examination of a preoperative patient, shortly after intraoperatively, and six weeks after the creation of a radiocephalic arteriovenous fistula. Parameters taken from the Doppler ultrasound examination were radial artery diameter, peak systolic velocity of the radial artery, the diameter of draining vein, volume flow draining, and distance of anastomosis to the skin surface. The reference standard in this study was maturation at the 6th week with maturity criteria if the venous diameter was at least $6 \mathrm{~mm}$, the volume flow rate of the vein was at least $600 \mathrm{~mL} / \mathrm{min}$, and the distance of anastomosis from the skin was a maximum of $6 \mathrm{~mm}$. Data will be processed using SPSS 20.0 for Windows ${ }^{\circledR}$.

\section{RESULTS}

From a total of 71 patients, the mean age of the patients was $53.75 \pm 7.82$ years. For gender distribution, males and females were $55.6 \%$ and $44.4 \%$, respectively. The mean blood flow rate was found $182.06 \pm 37.34 \mathrm{ml} / \mathrm{min}$, mean arterial diameter was $2.68 \pm 0.34 \mathrm{~mm}$, and the mean venous diameter was $2.55 \pm 0.33 \mathrm{~mm}$. The mean preoperative PSV was $45.36 \pm 1.99 \mathrm{~cm} / \mathrm{s}$, the mean

Table 2. Relationship between demographic, preoperative, and intraoperative variables with maturation of radiocephalic FAV.

\begin{tabular}{|c|c|c|c|}
\hline Variable & Mature & Immature & $\mathbf{p}$ \\
\hline Number of patients [n] & 48 & 23 & \\
\hline Age (years) $[$ mean \pm SD] & $53,35 \pm 8,48$ & $54,09 \pm 6,12$ & $0,712 * *$ \\
\hline \multicolumn{4}{|l|}{ Gender $[\mathrm{n}(\%)]$} \\
\hline Men & $29(75,2)$ & $11(27,5)$ & $0,456 *$ \\
\hline Women & $19(61,3)$ & $12(38,7)$ & \\
\hline \multicolumn{4}{|l|}{ Intraoperative data [mean \pm SD] } \\
\hline Bloodflow (ml/menit) & $201,85 \pm 27,85$ & $141,96 \pm 16,41$ & $<0,001 * *$ \\
\hline Diameter of artery (mm) & $2,69 \pm 0,38$ & $2,665 \pm 0,26$ & $0,755^{* *}$ \\
\hline Diameter of vein $(\mathrm{mm})$ & $2,54 \pm 0,35$ & $2,574 \pm 0,30$ & $0,525 * * *$ \\
\hline $\mathrm{SBP}(\mathrm{mmHg})$ & $131,98 \pm 10,35$ & $134,3 \pm 8,05$ & $0,252 * * *$ \\
\hline Preoperative PSV (cm/s) & $54,6+11,7$ & $26,7+7,7$ & $<0,001 * *$ \\
\hline Intraoperative PSV $(\mathrm{cm} / \mathrm{s})$ & $57,9+12,6$ & $27,1+8,1$ & $<0,001 * *$ \\
\hline Difference of PSV $(\mathrm{cm} / \mathrm{s})$ & 3 ( 0 s.d 5 ) & $0(-3$ s.d 2$)$ & $<0,001 * *$ \\
\hline
\end{tabular}

SBP, systolic blood pressure; AVF, arteriovenous fistula; PSV, Peak Systolic Velocity; *chi-square test;

**unpaired T test; ***Mann-Whitney test 
Table 3. Distribution of AUC, p value, and CI $95 \%$.

\begin{tabular}{lcccc}
\hline Test Result Variable(s) & Area & $\mathrm{p}$ & \multicolumn{2}{c}{$\begin{array}{c}9 \% \text { Confidence Interval } \\
\text { Upper Bound }\end{array}$} \\
\hline Preoperative PSV & & & Lower Bound & 1.000 \\
Intraoperative PSV & .973 & $<0.001$ & .940 & 1.000 \\
Difference in PSV & .974 & $<0.001$ & .942 & .991 \\
\hline
\end{tabular}

intraoperative PSV was $47.74 \pm 2.17 \mathrm{~cm} / \mathrm{s}$; and the mean PSV difference was $2.38 \pm 0.22 \mathrm{~cm} / \mathrm{s}$ (table 1).

About 23 patients (32.39\%) experienced failure of maturation. Blood flow rates, preoperative PSV, intraoperative PSV, and low PSV differences were associated with failure of maturation. While gender, arterial diameter, venous diameter, and systolic blood pressure in this study were found to had no significant effect on FAV maturity. In the preoperative PSV measurement for mature radiocephalic $F A V$, the average value was $54.6+$ $11.7 \mathrm{~cm} / \mathrm{s}$, while immature was $26.7+7.7 \mathrm{~cm} / \mathrm{s}$. Intraoperative PSV measurements for mature radiocephalic FAV obtained a mean value of $57.9+$ $12.6 \mathrm{~cm} / \mathrm{s}$, while immature was $27.1+8.1 \mathrm{~cm} / \mathrm{s}$. In the measurement of the difference between the preoperative with intraoperative PSV for mature radiocephalic $\mathrm{FAV}$, the average value of $3 \mathrm{~cm} / \mathrm{s}$ was obtained, while immature was $0 \mathrm{~cm} / \mathrm{s}$ (table 2 ).

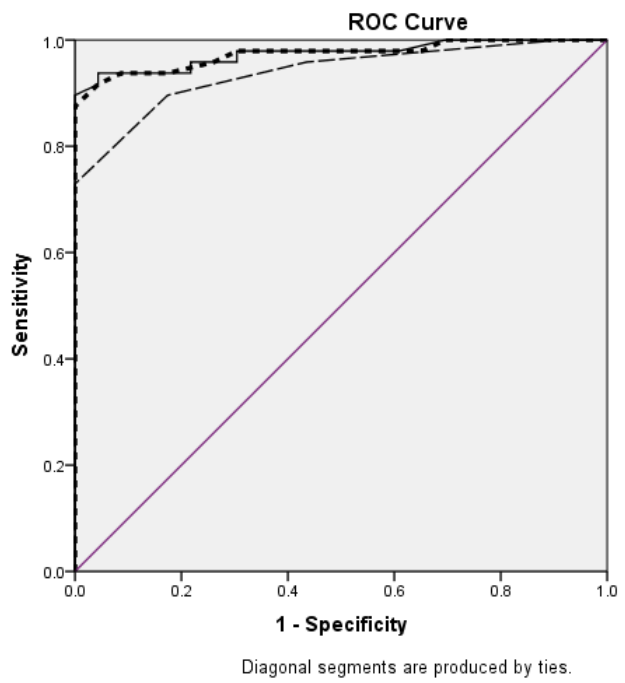

Source of th -PSV Intra ope --Selisih PSV - Reference L

Figure 1. ROC curve.

Then the ROC measurements for intraoperative PSV, preoperative PSV, and PSV difference were performed for radiocephalic FAV maturation (figure 1). For preoperative PSV, an area under curve (AUC) of $97.3 \%$ was obtained (CI $95 \%$ $94 \%-100 \%)$. The highest sensitivity and specificity values were obtained when the preoperative PSV value was $40 \mathrm{~cm} / \mathrm{s}$. For intraoperative PSV, an area under curve (AUC) of $97.4 \%$ was obtained (CI $95 \%$
$94.2 \%-100 \%)$. The highest sensitivity and specificity value obtained when the intraoperative PSV was $42 \mathrm{~cm} / \mathrm{s}$. For the difference between intraoperative and preoperative PSV, an area under curve (AUC) of $93.8 \%$ was obtained (CI 95\% 88.6\% $-99.1 \%)$. The highest sensitivity and specificity values were obtained when the difference between intraoperative and preoperative PSV was $2 \mathrm{~cm} / \mathrm{s}$. (table 3 and 4).

\section{DISCUSSION}

The factors that cause the failure of $A V$ fistula maturation can be many things. The most common cause is neointima hyperplasia that occurs in the anastomosis. Another possibility could be due to the technical operation that caused the anastomosis stricture, the poor quality of the veins, or the diameter of the blood vessels that were too small due to an error in the estimation of ultrasound mapping. ${ }^{11}$

Based on sex, this study differs from Miller et al. in this study we found no significant sex effects on AV fistula failure, where Miller et al. ${ }^{12}$ said that the failure of maturity was higher in female sex compared to male sex, although it can be noted that the characteristic in this study is that the percentage of maturity was higher in male $(75.2 \%)$ than female $(61.3 \%)$. Won et al. ${ }^{13}$ and Johnson et al. ${ }^{14}$ also proposed that sex was not associated with the failure of AV fistula maturity.

In this study, we also found that the diameter of the blood vessels did not significantly influence the maturity of the radiocephalic AV fistula. Various literature reports that blood vessel diameter was significantly related to maturity, where the failure rate was very high in blood vessel diameter below two mm. ${ }^{12,15,16}$ This may be due to different patient characteristics between studies.

In this study, it appeared that the measurement of preoperative PSV and interoperative PSV shortly after creation was good for predicting the maturity AV fistula. In this study, a preoperative PSV cut-off of $40 \mathrm{~cm} / \mathrm{s}$ was obtained as a predictor of whether or not the radiocephalic AV fistula will mature. This is close to the study reported by Sedlacek et al., ${ }^{9}$ which showed that the preoperative PSV in radiocephalic AV fistula of $>50 \mathrm{~cm} / \mathrm{s}$ as a predictor success of the maturity. While Lockhart et al. ${ }^{12}$ found that there was no significant difference between AV fistula maturity between preoperative PSV $<50 \mathrm{~cm} / \mathrm{s}$ and preoperative PSV $>50 \mathrm{~cm} / \mathrm{s}$, and between PSV difference of $<2 \mathrm{~cm} / \mathrm{s}$ and PSV

Table 4. Diagnostic test of preoperative PSV, intraoperative PSV, and PSV difference.

\begin{tabular}{lccccc}
\hline & Sensitivity & Specificity & PPV & NPV & Accuracy \\
\hline $\begin{array}{l}\text { Preoperative PSV (cut- } \\
\text { off } \geq 40 \mathrm{~cm} / \mathrm{s}\end{array}$ & 91,7 & 95,6 & 97,8 & 84,6 & 92,9 \\
& $(80,4-96,7 \%)$ & $(79,0-99,2 \%)$ & $(88,4-99,6 \%)$ & $(66,5-93,8 \%)$ & $(84,5-96,9)$ \\
Intraoperative PSV & 91,7 & 95,6 & 97,8 & 84,6 & 92,9 \\
(cut-off $\geq 42 \mathrm{~cm} / \mathrm{s})$ & $(80,4-96,7 \%)$ & $(79,0-99,2 \%)$ & $(88,4-99,6 \%)$ & $(66,5-93,8 \%)$ & $(84,5-96,9)$ \\
$\begin{array}{l}\text { Difference in PSV } \\
\text { (cut-off } \geq 2 \mathrm{~cm} / \mathrm{s})\end{array}$ & $(77,8-95,5 \%)$ & $(62,9-93,0 \%)$ & $(80,1-96,6 \%)$ & $(59,5-90,8 \%)$ & $(77,6-93,2 \%)$ \\
\hline
\end{tabular}


difference of $>2 \mathrm{~cm} / \mathrm{s}$. Measurements from the previous studies mentioned above were obtained by conducting intraoperative measurements using ultrasound devices with special probes with high sensitivity and accuracy of calculations so that differences are possible.

In this study, there was an increase in intraoperative PSV when compared with preoperative PSV; the mean value of the PSV difference was 2.38 $\pm 0.22 \mathrm{~cm} / \mathrm{s}$. A study conducted by Manos et al., ${ }^{17}$ explained that an increase in intraoperative PSV results from a decrease in peripheral resistance when the anastomosis is made, which causes increased blood flow in the proximal area of the anastomosis. Another study by McGahan et al. ${ }^{18}$ showed an increased of arteriovenous fistula peak systolic velocity and end-diastolic velocity. This occurs due to a decrease in resistance from arterial flow entering venous flow, as well as a decrease in the resistive index (difference in peak systolic velocity with end-diastolic velocity, divided by peak systolic velocity).

In this study, follow-up was limited to a period of 6 weeks before the patient performed hemodialysis to eliminate the effects of trauma associated with recurrent punctuation, where recurrent punctuation could cause stenotic or hemorrhagic complications which would reduce patency of AV fistulae. This is consistent with research conducted by Saucy et al., ${ }^{11}$ who also conducted a study in the period before cannulation.
This research had technical limitations where the procedure of AV fistulas was carried out by different people, although the operators were technically qualified to have the same standards and techniques, the approach and the way of treating could be different, and this could lead to bias.

\section{CONCLUSION}

In this study, it was found that the preoperative, intraoperative, and the difference between intraoperative and perioperative PSV with a cut-off value of $40 \mathrm{~cm} / \mathrm{s}, 42 \mathrm{~cm} / \mathrm{s}$, and $2 \mathrm{~cm} / \mathrm{s}$ respectively had a good predictor values and can be used as a tools to determine maturation in patients with FAV.

\section{ACKNOWLEDGMENTS}

The author states the original work, and there is no conflict of interest in doing this research.

\section{ORCID ID OF AUTHORS}

\author{
Dedy Pratama \\ https://orcid.org/0000-0003-2043-3084
}

Richard Yehuda Limen

https://orcid.org/0000-0002-7642-1691

Akhmadu Muradi

https://orcid.org/0000-0003-0165-9045

\section{REFERENCES}

1. Schulman G et al. The Kidney. Brenner BM Philadelphia: Elsevier Saunders 2004

2. Solesky BC, et al: Patient-centric analysis of dialysis access outcomes. J Vasc Access 11:31-37, 2010.

3. Timothy E. Bunchman, Klaus Konner, Alan Lumsden, et al. Vascular access 2006 work group membership. Am J Kidney Dis 2006; 48: S188-S247.

4. Alexander, J. Rely S. Profil Akses Vaskular pada Pasien Hemodialisa di RSUPN CiptoMangunkusumo 2012.

5. Rayner $\mathrm{HC}$, et al: Creation, cannulation and survival of arteriovenous fistulae: data from the Dialysis Outcomes and Practice Patterns Study. Kidney Int 63:323-330, 2003.

6. Dember LM, et al: Effect of clopidogrel on early failure of arteriovenous fistulas for hemodialysis: a randomized controlled trial. JAMA 299:2164-2171, 2008.

7. Patel ST, et al: Failure of arteriovenous fistula maturation: an unintended consequence of exceeding dialysis outcome quality initiative guidelines for hemodialysis access. J Vasc Surg 3:439-445, 2003.

8. Solesky BC, et al: Patient-centric analysis of dialysis access outcomes. J Vasc Access 11:31-37, 2010.

9. Sedlacek M, Teodorescu V, Falk A, Vassalotti J, Uribarri J.Hemodialysis access placement with preoperative non-invasive vascular mapping: comparison between patients with and without diabetes. AmJ Kidney Dis 2001;38:560-564.

10. Lockhart ME, Robbin ML, Allon M. Preoperative Sonographic Radial Artery Evaluation and Correlation With Subsequent Radiocephalic Fistula Outcome. J Ultrasound Med. 2004; 23:161-168.

11. Saucy F, Haesler E, Haller C, Déglise S, Teta D, Corpataux J, et al. Is intra-operative blood flow predictive for early failure of radiocephalic arteriovenous fistula? . Nephrol Dial Transplant 2010;25:862-7.

12. Miller C, Robbin M, Allon M. Gender differences in outcomes of arteriovenous fistulas in hemodialysis patients. Kidney Int 2003;63:346-52

13. Won T, Jang J, Lee S, Han J, Park Y, Ahn J. Effects of intraoperative blood flow on the early patency of radiocephalic fistulas. Ann Vasc Surg. 2000;14:468-72.

14. Joannides R, Haefeli W, Linder L, Richard V, Bakkali E, Thuillez C, et al. Nitric oxide is responsible for flow-dependent dilatation of human peripheral conduit arteries in vivo. Circulation. 1995;91:1314-9.

15. Wong V WR, Taylor J, Selvakumar S, How TV, Bakran, A. Factors associated with early failure of arteriovenous fistulae for haemodialysis access. Eur J Vasc Endovasc Surg. 1996;12:207-13.

16. Pratama D. Blood flow rate intraopertif sebagai prediktor maturitas fistula arteriovenous brakiosefalika. Program Pendidikan IImu Bedah FKUI. 2014. Unpublished.

17. Manos T, Varela AE, Moschos I, et al. Doppler Flow Indices At The Proximal And Distal Segment Of The Arteriovenous Shunt. EUROECHO. December 2009.

18. McGahan J, Teefey SA, Needleman L. General \& Vascular Ultrasound. $3^{\text {rd }}$ Edition. Elsevier. 2016: 44, 278, 228. 